\title{
Population aging and physician maldistribution: A longitudinal study in Japan
}

\author{
Kunichika Matsumoto, Kanako Seto, Shigeru Fujita, Takefumi Kitazawa, Tomonori Hasegawa* \\ Department of Social Medicine, Toho University School of Medicine, Tokyo, Japan
}

Received: September 9, 2015

Accepted: October 16, 2015

Online Published: October 22, 2015

DOI: $10.5430 /$ jha.v5n1p29

URL: http://dx.doi.org/10.5430/jha.v5n1p29

\begin{abstract}
Background: Over the past two decades, population aging and the introduction of the new postgraduate medical education program in 2004 have impacted on the geographic maldistribution of physicians in Japan. The purpose of this study was to evaluate recent changes in physician distribution across municipalities from 1996 to 2012 using Gini coefficients and to clarify the impact of the new medical education program on physician distribution.

Methods: We extracted the number of physicians classified by type of medical institution and municipal bodies. Gini coefficients were calculated using both population and demand for medical services. We calculated the contribution ratio (CR) of maldistribution within each type of medical institution to the whole maldistribution using Rao's method. In addition, we calculated the incremental difference in Gini coefficients between 2002 and 2010, and calculated the CR of the incremental Gini coefficient difference for each medical institution type using Seki's method.

Results: Both Gini coefficients decreased from 1996 to 2002, and increased after 2006. The CR of other hospitals increased from 2004. The incremental difference in the Gini coefficient using demand between 2002 and 2010 was 0.012 , and the CR of each type of medical institution was $-25.1 \%$ (university hospitals), $131.0 \%$ (other hospitals) and -5.9\% (clinics).

Conclusions: Our analysis showed that the geographic maldistribution of physicians has worsened since the introduction of the new postgraduate medical education program, and the CR of maldistribution in other hospitals was high. Our study suggested that new medical resource distribution policies should be discussed to improve maldistribution.
\end{abstract}

Key Words: Gini coefficient, Japan, Physician distribution, Population aging, Postgraduate medical education program

\section{INTRODUCTION}

The aging of Japan's population is advancing at an unprecedented speed. The aging rate (proportion of the elderly aged 65 or over) in 2014 was $28.7 \%$ and is expected to be $31.6 \%$ in 2030. ${ }^{[1]}$ Demand for health care services is high in the elderly. The total medical expenses per capita for people aged 65-74 years is 4.12 times higher, and that of those over 75 years is 5.10 times higher than that of those under 64 years old. Therefore, an increase in the elderly population will cause an increase of demand for health care services and an increase in national health expenditure.

Increasing demand for health care services also causes an increase in demand for physicians; however, the speed of aging differs across municipalities. Since 2000, the problem of physician shortages has been taken up in the media, and the maldistribution of physicians is now recognized as a social issue. ${ }^{[2]}$ The new postgraduate program for medical graduates was implemented in 2004 as part of Japan's health sector reform. Postgraduate clinical training for a 2-year period became mandatory, and graduates were able to choose teaching

\footnotetext{
*Correspondence: Tomonori Hasegawa; Email: tommie@med.toho-u.ac.jp; Address: Department of Social Medicine, Toho University School of Medicine, 5-21-16 Omorinishi, Ota-ku, Tokyo 143-8540, Japan.
} 
hospitals using a matching system. ${ }^{[3-5]}$ Before the new system was implemented, most graduates undertook training in university hospitals, and university hospitals had a role to supply physicians who had completed training to other hospitals. In 2003, 58.8\% of graduates undertook clinical training at university hospitals. This proportion decreased to $45.2 \%$ in 2013 (http://www.mhlw.go.jp/file/06-Seisaku jouhou-10800000-Iseikyoku/0000062068.pdf). University hospitals were forced to withdraw trained physicians from other hospitals to maintain their own medical offices. This resulted in a shortage of physicians, especially in rural areas.

There are several studies that show the trend of physician maldistribution in Japan. Most of them used Gini coefficient, which is the index of maldistribution. A value of 0 represents absolute equality, a value of 100 absolute inequality. Kobayashi et al. measured physician distribution across municipalities by a population-weighted Gini coefficient, and reported that the policy of establishing at least one medical school in each prefecture had led to an increase in the number of physicians, but had not improved the distribution of physicians. ${ }^{[6]}$ Matsumoto and Inoue also calculated the population-weighted Gini coefficient for physicians across municipalities, and reported that there was no remarkable improvement in distribution after $1990 .{ }^{[7-11]}$ Toyabe calculated the Gini coefficient, Atkinson index and Theil index across municipalities from 1996 to 2006 for university hospital physicians, other hospital physicians and clinic physicians, and found that for other hospital and university hospital physicians each index had increased after 2004, indicating that the new postgraduate program had exacerbated the geographical maldistribution of physicians. ${ }^{[12]}$ Sakai et al. measured pediatrician distribution across municipalities by a $0-14$ population-weighted Gini coefficient, and reported that the Gini coefficient had increased in urban prefectures after 2004. ${ }^{[13]}$ Tanihara et al. calculated the Gini coefficient for physicians in the secondary tiers of medical care as defined by the Medical Service Law and related legislation (medical administration areas which cover ordinary medical services such as general operations and emergency medicine) from 1998 to 2008, and reported the Gini coefficient decreased until 2006 but increased after 2006. ${ }^{[14]}$

Most previous studies used a population-weighted Gini coefficient for clinical physicians across municipalities or the secondary tiers of medical care based on official statistics. However, few studies have directed attention to disparities of aging rates across municipalities. The size of demand should be considered when discussing the appropriateness of physician supply. It is thought that more physicians are required in an area with a large elderly population, that is, large demand.
It is also necessary to survey the most recent situation to ascertain whether the impact of the new postgraduate program is temporary or long-term.

The present study aimed to evaluate recent changes in physician distribution across municipalities from 1996 to 2012 using Gini coefficients. We used two methods: the first analysis calculated the demand-weighted Gini coefficient in municipalities from 1996 to 2012. Demand was measured by the age structure of each municipality. The second analysis considered physician distribution by distribution within each institution type (intra-university hospitals, intra-other hospitals and intra-clinics), to calculate the contribution ratio (CR) for each distribution from 1996 to 2012. We quantitatively evaluated the impact of new postgraduate program by observing the $\mathrm{CR}$ change.

\section{MeTHODS}

\subsection{Data analyses}

In Japan, physicians must report their work place and clinical department to the Minister of Health, Labour and Welfare every two years. The Ministry of Health, Labour and Welfare has been publishing data on the number of clinical physicians in each municipality as the Survey of Physicians, Dentists and Pharmacists since 1972. This survey is the only data that comprehensively captures the number of physicians. The present study used the Survey of Physicians, Dentists and Pharmacists from 1996 to 2012, the period for which computerized data was available.

To determine the population of municipalities by 5 -year age groups, we used data from basic resident registers, compiled and published by the government. Since many municipalities merged during this period, we readjusted the numbers for physicians and population in each year, according to 2010 boundaries. The total number of municipalities was 1,865 .

\subsection{Gini coefficient}

The Gini coefficient is generally used to measure the geographical maldistribution of physicians ${ }^{[6-15]}$ and municipal population is usually used for weighting. The present study calculated the Gini coefficient using population, as well as the Gini coefficient using demand for medical services, measured by the age structure of each municipality. In Japan, unit costs of medical services (health care tariff) are determined by the central government and as a rule, the same tariff is applied to every age group and every municipality. Medical expense per capita is thought to reflect demand for medical services per capita. We used data for medical expenses per capita by 5-year age groups at 2012, and calculated the demand of each municipality by multiplying relative medical expenses per capita for each age group (medical expense per 
capita for all age groups is 1) by the age group population of each municipality. The group aged over 85 years had the most expensive relative medical expenses per capita (3.16); with expenses 13.4 times more than that of the 15-19 year old group (0.24).

\subsection{Decomposition of Gini coefficient and CRs of physi- cian distribution across university hospitals, other hospitals and clinics}

Clinical physicians' institutions were categorized as university hospitals, other hospitals and clinics. Physicians in each institution type may also face the problem of geographical maldistribution. We decomposed the Gini coefficient using Rao's method ${ }^{[16,17]}$ to factorize it by institution type. When $G$ is the overall Gini coefficient for physicians in municipalities, we can decompose $G$ as follows (see Equation 1):

$$
G=\sum_{i=1}^{m} W_{i} \cdot \bar{G}_{i}
$$

Where $i$ is the work institution (university hospitals, other hospitals or clinics), $\boldsymbol{W}_{\boldsymbol{i}}$ is the proportion of the number of physicians who work in institution $i$, and $\bar{G}_{i}$ is the pseudoGini coefficient (the numerical value obtained if municipalities are arrayed in increasing order of total number of physicians, rather than in increasing order of number of physicians from that factor). $\boldsymbol{W}_{\boldsymbol{i}} \cdot \overline{\boldsymbol{G}}_{\boldsymbol{i}}$ is the weighted pseudo-Gini coefficient, and proportion of $\boldsymbol{W}_{\boldsymbol{i}} \cdot \overline{\boldsymbol{G}}_{\boldsymbol{i}}$ to $G$ shows the CR for the maldistribution of physicians in institution $i$.

In addition, we compared the difference of $\mathrm{CR}$ to the change of G between 1996-2002 and 2002-2010, in order to evaluate the impact of the new postgraduate program. For that purpose, we used Seki's method. ${ }^{[17,18]}$ When the pseudo-Gini coefficient of factor $j$ (i.e., university hospital) at a time point $t$ is $\boldsymbol{R}_{t}^{j}$, we can represent the CR of the difference $\left(\Delta \boldsymbol{R}^{j}\right)$ from the pseudo-Gini coefficient of factor $j$ at a reference time point $\left(\boldsymbol{R}_{\mathbf{0}}^{j}\right)$ as follows (see Equation 2):

$$
\Delta R^{j}=W_{t}^{j} \cdot R_{t}^{j}-W_{0}^{j} \cdot R_{0}^{j}
$$

With $\frac{\Delta R^{j}}{\Delta G}$ showing the CR of factor $j$ to the change in $G$.

This study used only aggregated data, and did not use human or animals. In Japan, for this kind of study no institutional review is requested. ${ }^{[19]}$

\section{RESUlts}

\subsection{Trends in physician maldistribution}

From 1996 to 2012, the population of Japan increased by $1.4 \%$, and demand for medical services calculated by ageclassified population increased by $27.3 \%$. The relative in- crease of the elderly population was considered to result in higher demand for medical services. During this period, many municipalities merged, meaning the number of municipalities decreased from 3,371 in 1996 to 1,898 in 2012. Between 1996 and 2012, the number of clinical physicians increased from 240,908 to 303,268 (25.9\% increase).

Figure 1 shows the trends for the population Gini coefficient and the demand Gini coefficient. The demand Gini coefficient was consistently large, and the difference in both Gini coefficients increased. This means that if the difference in speed of aging in each area is considered, the problem of maldistribution of physicians gets more severe. Trends for both Gini coefficients were similar; decreasing until 2002 and increasing at 2004. After 2006, they increased consistently.

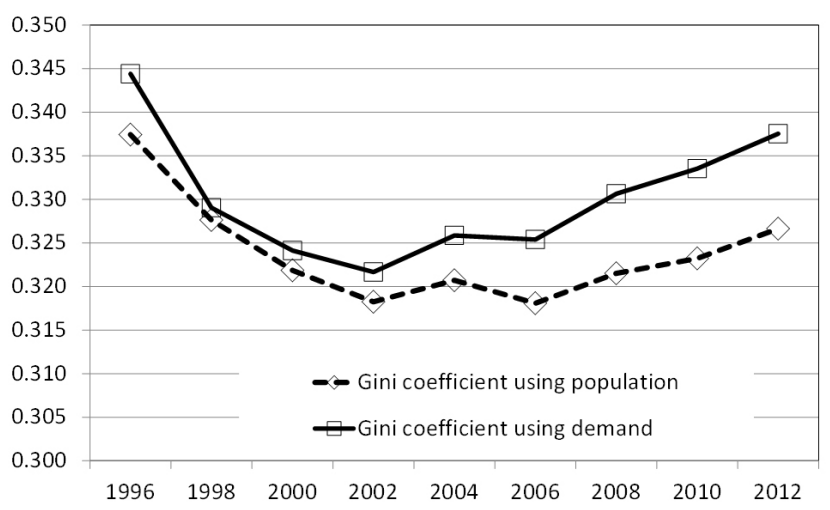

Figure 1. Trend of geographic maldistribution measured by Gini coefficient

\subsection{CR change of each institution type}

Table 1 shows the change in the CR of each institution to the overall Gini coefficient of physicians across municipalities. University hospitals had the highest CR for both Gini coefficients. After 2004, the CRs of university hospitals and clinics decreased, but the $\mathrm{CR}$ of other hospitals increased for both Gini coefficients.

\subsection{Overall Gini coefficient changes and institution CRs after introduction of the new postgraduate program}

Table 2 shows the change in the Gini coefficients and CR of each institution for 1996-2002 and for 2002-2010. During 1996-2002, the population Gini coefficient decreased by $0.019(5.7 \%)$ and the demand Gini coefficient decreased by $0.023(6.6 \%)$. The $\mathrm{CR}$ of each institution type to the change of population Gini coefficient was $47.3 \%$ for university hospitals, $28.0 \%$ for other hospitals and $24.7 \%$ for clinics. The CR of each institution type to the change of the demand Gini coefficient was $39.8 \%$ for university hospitals, $34.9 \%$ for other hospitals and $25.3 \%$ for clinics. The university hospitals CR was the highest, but the ratios of other institutions were also 
positive, meaning the change of distribution in all institutions contributed to the overall Gini coefficient decrease. However, for 2002-2010 (the new postgraduate program began in 2004), the population Gini coefficient increased by 0.005 $(1.6 \%)$ and the demand Gini coefficient increased by 0.012 (3.4\%). The CR of each institution type to the change of the population Gini coefficient was $-63.0 \%$ for university hospi- tals, $246.3 \%$ for other hospitals and $-83.3 \%$ for clinics. The CR of each institution type to the change of the demand Gini coefficient was $-25.1 \%$ for university hospitals, $131.0 \%$ for other hospitals and $-5.9 \%$ for clinics. The CR of university hospitals and clinics were negative, and only other hospitals contributed to the overall increase in the Gini coefficients.

Table 1. Contribution ratio of three groups (university hospitals, other hospitals and clinics) to total Gini coefficients

\begin{tabular}{|c|c|c|c|c|c|c|c|c|c|c|}
\hline & & $\begin{array}{l}1996 \\
\%\end{array}$ & $\begin{array}{l}1998 \\
\%\end{array}$ & $\begin{array}{l}2000 \\
\%\end{array}$ & $\begin{array}{l}2002 \\
\%\end{array}$ & $\begin{array}{l}2004 \\
\%\end{array}$ & $\begin{array}{l}2006 \\
\%\end{array}$ & $\begin{array}{l}2008 \\
\%\end{array}$ & $\begin{array}{l}2010 \\
\%\end{array}$ & $\begin{array}{l}2012 \\
\%\end{array}$ \\
\hline \multirow{3}{*}{$\begin{array}{l}\text { Gini coefficient } \\
\text { using population }\end{array}$} & University Hospital & 43.8 & 43.4 & 43.2 & 43.6 & 42.6 & 41.9 & 42.1 & 41.9 & 42.1 \\
\hline & Other Hospital & 38.3 & 39.1 & 39.0 & 39.0 & 40.2 & 41.4 & 41.9 & 42.1 & 42.4 \\
\hline & Clinic & 17.9 & 17.5 & 17.8 & 17.5 & 17.2 & 16.7 & 16.1 & 15.9 & 15.6 \\
\hline \multirow{3}{*}{$\begin{array}{l}\text { Gini coefficient } \\
\text { using demand }\end{array}$} & University Hospital & 43.9 & 44.2 & 43.8 & 44.2 & 42.9 & 42.2 & 41.9 & 41.7 & 41.7 \\
\hline & Other Hospital & 37.8 & 38.4 & 38.2 & 38.0 & 39.3 & 40.4 & 41.1 & 41.4 & 41.7 \\
\hline & Clinic & 18.3 & 17.4 & 17.9 & 17.8 & 17.7 & 17.4 & 17.1 & 16.9 & 16.7 \\
\hline
\end{tabular}

Table 2. Contribution degree and contribution ratio of three groups (university hospitals, other hospitals and clinics) to the change of Gini coefficients

\begin{tabular}{|c|c|c|c|c|c|}
\hline & & \multicolumn{2}{|c|}{$1996 \rightarrow 2002$} & \multicolumn{2}{|c|}{$2002 \rightarrow 2010$} \\
\hline & & $\begin{array}{l}\text { Gini coefficient using } \\
\text { population }\end{array}$ & $\begin{array}{l}\text { Gini coefficient using } \\
\text { demand }\end{array}$ & $\begin{array}{l}\text { Gini coefficient using } \\
\text { population }\end{array}$ & $\begin{array}{l}\text { Gini coefficient using } \\
\text { demand }\end{array}$ \\
\hline \multicolumn{2}{|c|}{ Change of Gini Coefficient } & $-0.019(-5.7 \%)$ & $-0.023(-6.6 \%)$ & $+0.005(+1.6 \%)$ & $+0.012(+3.4 \%)$ \\
\hline \multirow{3}{*}{$\begin{array}{l}\text { Contribution } \\
\text { degree }\end{array}$} & University Hospital & -0.00907 & -0.00905 & -0.0031 & -0.0030 \\
\hline & Other Hospital & -0.00536 & -0.00794 & 0.0122 & 0.0156 \\
\hline & Clinic & -0.00473 & -0.00576 & -0.0041 & -0.0007 \\
\hline \multirow{3}{*}{$\begin{array}{l}\text { Contribution } \\
\text { ratio }(\%)\end{array}$} & University Hospital & 47.3 & 39.8 & -63.0 & -25.1 \\
\hline & Other Hospital & 28.0 & 34.9 & 246.3 & 131.0 \\
\hline & Clinic & 24.7 & 25.3 & -83.3 & -5.9 \\
\hline
\end{tabular}

\section{Discussion}

We measured the geographic maldistribution of clinical physicians in Japan using Gini coefficients and found that the problem of maldistribution had been resolving until 2002. However, since 2006, maldistribution has been becoming worse. We also found that maldistribution weighted by demand for medical services was always higher than maldistribution weighted by population. The CR of university hospitals to the overall Gini coefficient was the highest but had been decreasing since 2004. In addition, it became clear that for 1996-2002 the overall Gini coefficient was in a downturn phase and all three institution types contributed to this trend. However, after the introduction of the new postgraduate program, only maldistribution for other hospitals deteriorated, resulting in a deterioration of the maldistribution of physicians overall.

The results of our study support those of previous studies which reported deterioration of the geographic maldistribution of physicians after the introduction of the new post- graduate program. Our findings showed a continuous Gini coefficient increase after 2006, even when weighted by demand for medical services. This suggests that the problem of the geographic maldistribution of physicians has become worse.

Our results also suggested that the withdrawal of physicians from local hospitals to secure university hospital physicians resulted in deterioration of the maldistribution of physicians. After 2004, many graduates selected other hospitals as training hospitals but they tend to prefer well-known hospitals located in urban areas. There is a possibility that this exacerbates the geographic maldistribution in other hospitals.

The new postgraduate education program imposes at least two years of postgraduate clinical training on graduates to improve their ability in clinical practice. In Japan, there is no compulsory policy to resolve the geographical maldistribution of physicians, ${ }^{[20]}$ and there is a criticism that previous policies do not fully perform their function as solutions. ${ }^{[6,14]}$ In 2010, the Japanese government encouraged 
medical schools to increase their quotas and to introduce a selective admission policy for medically underserved areas and clinical departments. Further investigation is needed to evaluate the impact of these policies. Implementing the new postgraduate policy without a compulsory policy to resolve the geographical maldistribution of physicians may have contributed to further geographical maldistribution of physicians. The geographical maldistribution of physicians is major problem for many countries and it is a difficult problem to resolve. To develop effective solutions, universities, medical associations, medical institutes and government should collaborate.

\section{Conclusion}

The geographic distribution of physicians in Japan had been improving until the early 2000 s, but has deteriorated since
2004, when the new postgraduate program was introduced. Geographic maldistribution in other hospitals contributed to the overall maldistribution. Medical quality improvement is a responsibility shared by the medical community, meaning that at the same time, the improvement of the geographic distribution of physicians should also be addressed by the entire medical community.

\section{Funding}

This work was supported by JSPS KAKENHI Grant Number 24590638.

\section{CONFLICTS OF INTEREST Disclosure}

The authors report no financial conflict of interest.

\section{REFERENCES}

[1] National Institution of Population and Social Security Research. Population Projection for Japan 2014. Accessed 20 May 2015. Available from: http://www.ipss.go.jp/syoushika/tohkei/ newest04/sh2401top.html

[2] Matsumoto K, Kitazawa T, Ito S, et al. Study on supply, demand and distribution of physicians in Japan. The Journal of Japan Society for Health Care Management. 2010; 10(4): 575-582.

[3] Suzuki Y. Medical education in Japan: a challenge to the healthcare system. Med Teach. 2008; 30(9-10): 846-50. PMid: 19117222. http://dx.doi.org/10.1080/01421590802298207

[4] Kozu T. Medical Education in Japan. Academic Medicine. 2006; 81(12): 1069-75. PMid: 17122471. http://dx.doi.org/10.10 97/01. ACM. $0000246682.45610 . d d$

[5] Teo A. The current state of medical education in Japan: a system under reform. Med Educ. 2007; 41(3): 302-8. PMid: 17316216. http://dx.doi.org/10.1111/j.1365-2929.2007.02691.x

[6] Kobayashi Y, Takaki H. Geographic distribution of physicians in Japan. The Lancet. 1992; 340(8832): 1391-3. http://dx. doi .org /10.1016/0140-6736 (92) 92569-2

[7] Noue K, Matsumoto M, Toyokawa S, et al. Transition of physician distribution (1980-2002) in Japan and factors predicting future rural practice, Rural Remote Health. 2009; 9(2): 1070. PMid: 19463042.

[8] Matsumoto M, Inoue K, Farmer J, et al. Geographic distribution of primary care physicians in Japan and Britain. Health Place. 2010; 16(1): 164-6. PMid: 19733111. http://dx.doi.org/10.1016/j .healthplace. 2009.07.005

[9] Matsumoto M, Inoue K, Bowman R, et al. Geographical distribution of physicians in Japan and US: Impact of healthcare system on physician dispersal pattern. Health Policy. 2010; 96(3): 255-61. PMid: 20236722. http://dx.doi.org/10.1016/j . healthpol. 2010. 02.012

[10] Matsumoto M, Inoue K, Bowman R, et al. Physician scarcity is a predictor of further scarcity in US, and a predictor of concentration in Japan. Health Policy. 2010; 95(2-3): 129-36. PMid: 20004995. http://dx.doi.org/10.1016/j.healthpol.2009.11.012

[11] Matsumoto M, Inoue K, Bowman R, et al. Self-employment, specialty choice, and geographical distribution of physicians in Japan:
A comparison with the United States. Health Policy. 2010; 96(3): 239-44. PMid: 20223549. http://dx.doi.org/10.1016/j.hea lthpol.2010.02.008

[12] Toyabe S. Trend in geographic distribution of physicians in Japan Int J Equity Health. 2009; 8: 5. PMid: 19257879. http://dx. doi .org/10.1186/1475-9276-8-5

[13] Sakai R, Wang W, Yamaguchi N, et al. The impact of Japan's 2004 postgraduate training program on intra-prefectural distribution of pediatricians in Japan. PLoS One. 2013; 8(10): e77045. PMid: 24204731. http://dx.doi.org/10.1371/journal . pon e. 0077045

[14] Tanihara S, Kobayashi Y, Une H, et al. Urbanization and physician maldistribution: a longitudinal study in Japan. BMC Health Services Research. 2011; 11: 260. PMid: 21982582. http://dx.doi.org /10.1186/1472-6963-11-260

[15] Brown MC. Using Gini-style indices to evaluate the spatial patterns of health practitioners: theoretical considerations and an application based on Alberta data. Soc Sci Med. 1994; 38(9): 1243-56. http://dx.doi .org/10.1016/0277-9536(94)90189-9

[16] Rao VM. Two decomposition of concentration ratio, Journal of Royal Statistical Association, series A. 1969; 132(3): 418-425. http://dx.doi.org/10.2307/2344120

[17] Kimura K. The effectiveness of Gini coefficient. In: The concentration ratio in historical perspective. Sapporo: Hokkaido daigaku shuppankai; 2008. 308-311 (in Japanese).

[18] Seki Y. Decomposition method of contribution degree of Gini coefficient. In: Seki Y. Contribution degree and contribution ratio: decomposition method of contribution degree of increase rate. Tokyo Sengyo tokei kenkyusha; 1992. 163-190 (in Japanese).

[19] Ethical Guidelines for Epidemiological Research. Accessed on May 20, 2015. Available from: http://www.lifescience.mext.go. jp/files/pdf/n796_01.pdf

[20] Ozegowski S. Effective policy mechanisms for an equitable geographical distribution of general practitioners: a qualitative comparative analysis of the accessibility of primary care in Europe. $\mathbf{J}$ Health Serv Res Policy. 2013; 18(3): 151-159. PMid: 23864419. http://dx.doi.org/10.1177/1355819613482885 